\title{
FOOD SAFETY IN HOSPITALITY INDUSTRY
}

\author{
Hari Purnomo \\ Professor in Animal Food Technology, Faculty of Animal Husbandry, Brawijaya University, Malang \\ e-mail: purnomo.hari@lycos.com
}

\begin{abstract}
As food safety includes food hygiene, hazard related to food and its risks is becoming an important issue to consumers making purchase decisions. Therefore, the food processors and food handlers either in hospitality and food processing industries should improve their knowledge and skill on food safety assurance. A systematic and continued training and education with behavioural changes, and supported with good law enforcement are likely to minimize the hazard related to food and its risks.
\end{abstract}

Keywords: food safety, hospitality industry.

The rapid technological changes in all aspects of life to a certain extent have affected the food pattern and food habit of people especially in the metropolitan areas. These changes also bring the impressive growth of hospitality industries such as international and national tourism, restaurants, fastfood outlets and catering businesses.

Cartwright (2003) noted that the World Tourism Organisation had recorded an increase of $7.4 \%$ of tourist in the year 2000 , which brings the total number of international arrivals up to 699 million, and this increasing number of tourist bringing the people eating more outside their homes. Everet (2000) reported that in the United States over the past several years, Americans have begun eating more meals in restaurants. Hence, the control of their food safety is now moving from the housewives to the food handlers in the food outlets and it is indirectly also enforced the local health departments to imply a strict food safety standard.

The food pattern, food habit and other newly developed technologies increased the importance of food safety management systems, as the food supply chain sources as well as consumers become more knowledgeable and discerning on all issues associated with food particularly the one related to food safety.

\section{FOOD SAFETY}

Food is an essential part of life, but if it is contaminated it can cause illness even death, and food can be contaminated with toxic substances from outside or even it is already in the food itself. There are possibilities of contamination with microbiological, chemical and/or physical hazards with or without the growth of micro organisms in each step of food preparations.

Griffith (2006) noted that according to Roberts (2002) there could be some confusion due to a range of terms known in the literature as food poisoning, food borne illness and food borne disease. Some of the food are naturally poisonous, but some other may go through a prolonged and increasingly process from farm or producer to the point of consumption.

According to Schmidt (1995), the World Health Organisation (WHO) defined the food and water borne illness as regardless of the presenting symptoms and includes any disease of an infectious or toxic nature caused by or thought to be cause by the consumption of food or water. Therefore food and water borne disease is caused by various microbiological, chemical and physical hazard includes illness which may be present in food or water.

Food safety synonymous with food hygiene embracing anything in the processing, preparation or handling of food to ensure it is safe to eat (Griffith, 2006). While Yeung and Morris (2001) noted that a hazard is an activity or process which can result in negative consequences and thereby provide a source of risk to receiving environment or population. Furthermore they suggested that the identification of food hazard can be used as the beginning of analysing the risk relating to the food safety. Rhodehamel (1992) cited the definition of hazard from The National Advisory Committee on Microbiological Criteria for Foods (NACMCF) as any biological, chemical or physical property that may cause an unacceptable consumers health risks.

A food safety can be defined as "the maximum frequency and/or concentration of a (microbiological) hazard in food at the time of consumption that provides the appropriate level of health protection". Some scientists think of food safety in terms of hazard and risks (Anonymous, 2003). Griffith (2006) had reviewed the history of food safety and presented a model for studying food 
safety. A timeline of ood safety had also been listed and he recorded that food safety had been known since $5000 \mathrm{BC}$, where people avoided the food contain natural toxic. Early time of fermentation $(4000 \mathrm{BC})$ as well as people knowing food safety in related to religious beliefs $(2500 \mathrm{BC})$ were also recorded. The first recognition of existence of micro organism by Antonie van Leuwenhoek in 1676, the founding of basis of commercial heat processing by Louis Pasteur in 1857 up to the Food Safety (General Food Hygiene) regulation in Europe in 1995 were also the part of the history of food safety in human life. Furthermore he noted that the estimation of the size of risks that the hazard will occur can be first identified by the hazard which related to foods or food components. Thus the food safety should reduce the size of risks to minimum level without severe disruption of the food supply.

In the last decades the consumers' consciousness about health issues related to their food are increased, especially in developed countries which affected the food producers and related institutes to present better information on food safety. Smed and Jensen (2005) had studied the needs of food safety information and food demand. In their study they examined the effect of negative press coverage of Salmonella in shell eggs on the demand for pasteurised eggs. The results showed that negative safety news about one product can provide a significant stimulation on the demand for other products. Therefore, food safety awareness of consumers will influence the demand of the products.

Food safety nowadays has become a very important issue to be discussed and also become a considerable and increasing interest in many sectors including hospitality industry, food and beverage industry, government officials and public health institutions.

\section{HAZARD RELATED TO FOOD}

As pointed earlier, hazard related to food is due to biological, chemical and physical contamination which can cause a food poisoning, food borne illness and/or food borne disease. The largest cause of the outbreaks is improper food preparation, handling and storage; where most of these activities occurring in homes, institutions or restaurants. Based on the relation of hazard to food there are three broad general categories of hazard namely biological or microbiological hazard, chemical hazard and physical hazard.

\section{Biological or Microbiological Hazard}

This hazard is mainly caused by bacteria, fungal, viral and parasitic (protozoa and worms) micro organisms and/or their toxin. There are only few pathogenic micro organisms related with food, which cause illness and disease; and these micro organisms are usually known as food pathogens. Potter and Hotchkiss (1995) grouped the hazardous micro organisms and parasites based on their risk severity into a group of severe hazard micro organisms, moderate hazard with potentially extensive spread micro organisms and moderate hazard with limited spread micro organisms.

It is important to note that there are two types of food borne disease caused by the food pathogens micro organisms (i.e infections and intoxications). If the viable food pathogenic micro organisms are ingested and multiply within the body and produce disease, it is called as infections. On the other hand if the toxins are produced by those food pathogenic micro organisms within the food, then consuming it can cause intoxications. Intoxications can occur even if no viable micro organisms are ingested, and this condition usually occurs in stored food where food pathogenic micro organisms grow and produced toxin. Although processing of food may destroy the food pathogenic micro organisms, but such treatments do not destroy the toxin which is already within the food.

Microbiological hazard has become an interesting research object and has been studied intensively in the aspects of the factors influencing their occurrence, growth and multiplication in food and the level of the risks they cause. Similarly, there is also sufficient literature on the risks of practices, procedures and processes which often lead to outbreaks of food borne diseases (Waiters and Arbunott, 1990; Potter and Hotchkiss, 1992; Ehiri and Morris, 1994; Baird-Parker, 1994; Jay, 1996; Anonymous, 2000; Dalton et al., 2000 and Cartwright, 2003)

Hardie et al. (1999) reported that the outbreak of infectious diarrhoea with 70 laboratory confirmed cases and 107 probable cases occurred in a hotel in Greece. They also noted that the outbreaks of giardiasis illness due to consuming food contaminated with pathogenic micro organism: Giardia lamblia, was the largest since 1985 in the United Kingdom and at first it was identified in tourist returning from abroad.

Love et al. (2002) also reported a large outbreak of acute gastroenteritis which occurred among three groups of guests and hotel employees in Virginia. It is believed that food was the probable source for the guests, and the disease was continued 
spreading in the hotel by food, environmental contamination and/or person-to-person transmission through infected guests and employees.

It is interesting to note that Florez et al (2005) also observed gastroenteritis outbreaks in both developing and industrialised countries where the pathogen micro organism: Shigella sonnei was the significant micro organism caused that outbreaks. Furthermore they noted that the ingestions of food contaminated with infectious or toxigenic micro organisms is a major cause of morbidity and a very significant cause of death throughout the world.

\section{Chemical Hazard}

Chemicals which cause a hazard associated with food can be classified as naturally occurring indirectly and directly added. Naturally occurring chemicals which cause a hazard in food are toxicant that already exist in the food itself such as histamine in seafood can cause an allergy or intoxication, mushroom toxins and mycotoxin in certain variety of legumes. Those toxicants can be considered as fast acting toxicants which mean that it can directly cause illness after ingestion. However some natural foods also contain slow acting toxicants, where if it is consumed over a long period of time it could potentially promote chronic disease and called as carcinogenic substances (Potter and Hotchkiss, 1995; O'Keefe and Kennedy, 1998).

O'Keefe and Kennedy (1998) also reported that there are chemicals derived from processing such as nitrosamines and plasticizers from packagin materials which are harmful if it is consumed for long period of time. They also observed that contaminants arising in domestic food preparation such as heavy metals and agrochemicals residue pesticides, insecticides) as well as veterinary drug (antibiotics, growth hormones) known as indirectly added chemicals. If it is ingested, they may pose hazards to human health. Therefore, develop countries as described by Sanders (1999) monitored, controlled, regulated and reviewed strictly the use of agrochemicals and veterinary drugs.

Käferstein and Abdulsallam (1999) had reported the toxic chemicals released into the environment by industrial processes and agricultura practices may enter the human food chain. They also concerned with the increase amount of industria waste released in the environment as well as the excess use of agrochemicals especially in the developing countries in the long term could promote a hazard to the food in that region.

Chemicals which are intentionally and directly added to foods in regulated small amounts is known as food additive. Most of these food additives are chemical synthetic substances although some of them are naturally originated. Some scientists defined food additive as any substance added to food for a specific purpose (Lewis, 1995 and Branen et al., 2002).

Potter and Hotchkiss (1995) and Branen et al.(2002) grouped the food additives based on their functional properties, and there are 12 groups of it The functional properties of these food additives are as preservatives, antioxidants, sequesterants, surface active agents, stabilizers and thickeners, bleaching and maturing agents such as starch modifiers, buffers (acids and alkilines), food colour, artificial sweeteners, nutritional additives, flavouring agents and miscellaneous additives such as food additive provide functions other than those already mentioned i.e. growth promoter of bakers' yeast, firming agen for fruit and vegetable, anticaking agent, antisticking agent and many more.

In their recent studies, Park and Lewis (1992) found that the use of food preservatives such as benzoic acid, nitrites and sulphites as antimicrobial agent and Butylated Hydroxy Anisole (BHA), Butylated Hydroxy Toluene (BHT), ascorbic acid and tocopherol as antioxidants have probably changed food productions patterns and eating habits more than the use of any other class of food additive. These food preservatives chemicals will offer substantial benefits on man not only by the preservation and increased palatability of food, but also by its function to protect against the pathogenical affects of reactive oxygen species micro organisms which associated with cancer, cardiovascular disease and aging.

The important issue where food processors and food handler should be aware of is that the usage of food additives are regulated by the Food and Drug Administration or by the Department of Health in each country as well as listed in the International and/or National Standard agencies such as Codex Allimentarius (WHO/FAO). There are guidelines to be followed and where it listed the food additives can be used and the maximum amount permitted to be added to foods. Unfortunately due to lack of knowledge or information, there are still some food processors or producers using the non-listed food additives or chemicals which are not for food such as formalin or borax in their food products. Some of them are also using an excessive amount of permitted food additive, where such of misused practices will promote a health hazard to the consumers.

\section{Physical Hazard}


The physical hazard usually occurs when food contaminated with environmental contaminants during processing and packaging is consumed. Potter and Hotchkiss (1995) noted that main materials concern as physical hazards are glass fragments, cuts of wood, stones, small piece of metal such as paper clip and other filth, insulation material and some other personal effects. Those contaminants if ingested could give some health risk and for this reason especially for metal contaminants, food processors use an electronic metal detector which screen the products from metal contaminants.

Bennion (1992) and Potter and Hotchkiss (1995) suggested that to reduce the risks of those physical contaminants, the food processors and producers should implement the good manufacturing practices and careful analysis of the critical control points in their production line. This program is actually a part of the well known Hazard Analysis Critical Control Points (HACCP) system.

FOOD SAFETY IN HOSPITALITY INDUSTRY

Food technology development in the last decades brings both market opportunities and food safety perils. Therefore food safety has become major interest in many sectors including hospitality industry, food processing industry, government institutes and public health agencies.

Those involve in food preparation and service play a vital role in the prevention of food borne illness and/or food borne disease and their actions can be critical in preventing outbreaks of food borne illness and/or food borne disease. Hence preventing the outbreaks is more a matter of understanding where food borne disease originates and how food manufacturing and storage can increase the risks of that disease. This understanding should belong not only to the food handlers but also the managers of industries related to food as well as the consumers themselves.

The best and most effective method of assuring food safety is to establish a systematic and continuous training and education for the food handlers in hospitality and food processing industries, managers of hospitality and food processing industries, government officers in charge with food safety as well as the consumers. Once the food safety issues are understood the hazard and its risks in foods can be minimized.

However, Clayton et al. (2002) found that although the number of food handlers receiving food safety training is increased, a high proportion of food poisoning outbreaks still occur as a result of poor food handling. This study also highlights the need of training based on a risk-based approach and demonstrates that behavioural changes will not occur merely as a result of training only.

Willson et al (1998) observed that although the concept of training is endorsed by many managers in the hospitality industries, only very few managers put these ideas into practice. Whilst, Go et al. (1996) defined the hospitality training as a systematic process through which an organisation's human resources gain knowledge and develop skills by instruction and practical activities that result in improved corporate performance. Furthermore they noted that the effective achievement can be obtained from repeated learning measures and not a one time activity.

Krammer and Scott (2004) noted that safe food handling in ready-to-eat food establishment is a basic element in the reduction of food borne disease and it can give a better food safety assurance for their consumers. Whilst Kidd (2000) had discussed the consumers concern on food safety, he observed that the consumer is concerned about a lack of information and knowledge, and they feel that there is a corruption about the facts.

Besides education and training, the food legislation also plays a supportive role for the success of the food safety assurance. Adams (1995) had reviewed the past and present food hygiene legislation and made a recommendation in the production of an industrial guide for food safety in the hotel and catering industries.

\section{CONCLUSION}

Food safety includes food hygiene, hazard related to food and its risks become important issues if we are preparing and handling safe foods Microbiological hazard is the most considerable and increasing interest in the food safety programmes as the outbreaks are world wide and also can be a transnational issue.

Chemical hazard is less crucial, but it needs a special attention especially in developing countries, where most of the food processors and food handlers quite often misused those chemicals in foods. The excessive amount of permitted chemicals and the non-food grade chemicals are still found in foods especially in developing countries.

Knowledge and attitudes related to food safety are critical among the hospitality industry managers who will supervise their food handlers in preparing foods in their food outlets. The food legislation and education with emphasis on the later 
can give a food safety assurance. However it should involve the behavioural change and enable people to set and implement their own food safety agenda. Therefore integrated education, training, behavioura change, food legislation and the consciousness of food handlers, government officers in charge with food safety, educators in hospitality studies and consumers are necessary together to minimize the unintended consequences from the technological development and its hazard and risks related to food. So how will this information contribute in food safety assurance in hospitality industry in the future and what can we hope to achieve? The answer is that in meeting the huge challenge in food safety in the $21^{\text {st }}$ century, all people who are concerned and related to safe food should be encouraged to obtain and maintain a current food safety knowledge.

\section{REFERENCES}

Adams, A. (1995). Food safety the formal solution for the hotel and catering industry? British Food Journal, 97, (4), pp. 19-23.

Anonymous. (2000). Microbiological status of ready to eat fruit and vegetables, Discussion paper $\mathrm{ACM} / 476$, London.

Anonymous. (2003). Impact of food safety objectives on microbiological food safety management. ISLI Europe, Newsletter No. 51.

Baird-Parker, A.C. (1994). Foods and microbiological risks. Microbiology, 140, pp. 687-695.

Bennion, M. (1992). Introductory foods. ( $\left.7^{\text {th }} \mathrm{ed}\right)$, New York: MacMillan Publishing Co.Inc.

Branen, A. L., Davidson, P. M., and Salminen, S. (2002). Food Additive. New York: Marcel Dekker A.G.

Cartwright, R.Y. (2003). Food and waterborne infections associated with package holiday. Journal Applied Microbiology, 94, pp. 12S-24S.

Clayton, D. A., Griffith, C. J., Price, P., and Peters, A. C. (2002) Food handlers belief and self reported practices. Journal of Environmental Health Research, 12, (1), pp. 25-39.

Dalton, C. B., Gregory, J., Kerk, M. D., Stafford, R J., and Goula, D. (2004). Foodborne disease outbreaks in Australia. Communicable Disease Intelligence, 28, (2), pp. 211-234.

Ehiri, J. E., and Morris, G.P. (1994). Food safety control strategies: A critical review of tra- ditional approaches. Journal of Environmental Health Research, 4, (4), pp. 254-263.

Everett, K. (2000). Standards of foodsafety in Hamilton country restaurants. Report of Capstone Research, February 23, Hamilton.

Florez, J. A., Roth, E. P., Linares, S. G., and Alvarez, S. M. (2005). Outbreaks of Shigella sonnei in a rural hotel in La Gomera Cannary Islands, Spain. International Microbiology, 8, (2), pp. 133-136.

Go, F. M., Monachello, M. L., and Baun, T. (1996) Human Resource Management in the Hospitalty Industry. New York: J.Willey \& Sons.

Griffith, C. J. (2006). Food safety where from and where to. British Food Journal, 108, (1), pp 6-15.

Hardie, R. M., Wall, P. G., Go, H. P., Bardhan, M. and Barleth, C. R. L. (1999). Infections diarrhea in tourists staying in a resort hotel. Emerging Infection Disease, 5, (1), pp. 168171.

Jay, J. A. (1992). Modern Food Microbiology. New York: Van Nostrand Reinhold Company.

Käferstein, F., and Abdulsallam, M. (1999). Food safety in the $21^{\text {st }}$ century. Bulletin of the World Health Organisatio, 77, (4), pp. 347-351.

Kidd, M. (2000). Food safety consumers concern. Nutrition and Food Science, 30, (2), pp. 53-55.

Kramer, J., and Scott, W. G. (2004). Food safety knowledge and practices in ready-to-eat establishment. Journal of Environmental Health Research, 14, (5), pp. 343-350.

Lewis, R. J. (1995). Food Additive Handbook. New York. Springer Verlag Inc.

Love, S. S., Jiang, X., Barett, F., Farkes, I., and Kelly, S. (2002). A large hotel outbreak of Norwalk like virus gastroenteritis among three groups of guests and hotel employees in Virginia. Epidemiology and Infections, 129, pp. 127-132.

O'Keefe, M., and Kennedy, O. (1998). Residue: A food safety problem? Journal Food Safety, 18 (4), pp. 297-319.

Park, D. V., and Lewis, D. F. (1992). Safety aspects of food preservatives. Food Additive Contamination, 9, (5), pp. 561-577.

Potter, N. N., and Hotchkiss, J. H. (1995). Food Science. ( $\left.5^{\text {th }} \mathrm{ed}\right)$, London: Chapman \& Hall. 
Rhodehamel, E. J., (1992). Overview of biological, chemical and physical hazards. In: HACCP Principles and Applications .(Ed: Pierson, M.D., and Corlett Jr,D.A.), London: Chapman $\&$ Hall

Sanders, T. A. B. (1999). Food production and food safety. British Marketing Journal, 318, pp. 1689-1693.

Schmidt, K. (1995). WHO surveillance programme for control of food borne infections and intoxications in Europe Berlin, Federal Institute for Health Protection of Consumers and Veterinary Medicine, $6^{\text {th }}$ report 19901992.

Waiters, W. M., and Arbrunott, J. P. (1990). Foodborne illness an overview. Lancet, 336, pp. 722-725

Wilson, M. D. J., Murray, A. E., Black, M. A., and Dowell, D. A. Ac. (1998). Training and education in contract catering management. Journal of European Industrial Training, 22, (3), pp. 73-81.

Smed, S., and Jensen, J. D. (2005). Food safety information and food demand. British Food Journal, 107, (3), pp. 173-186.

Yeung, R. M. W., and Morris, J. (2001). Food safety risk: Consumer perception and purchase behavior. British Food Journal, 103, (3), pp. 170-186. 